\title{
Studi numerik kekuatan material transmisi roda gigi pico hydro
}

\author{
Akhmad Nurdin'1, Dwi Aries Himawanto \\ ${ }^{1,2}$ Jurusan Teknik Mesin - Universitas Sebelas Maret \\ Jl. Ir. Sutami No.36 A Surakarta \\ Email korespondensi: akhmadnurdin.89@student.uns.ac.id
}

\begin{abstract}
Abstrak :
Generator bekerja dengan optimal saat sistem penggerak mengirimkan daya turbin dengan arah putaran dan kecepatan yang sesuai. Tegangan bending dan tegangan kontak pada roda gigi serta tegangan geser pada poros perlu diperhatikan dalam merancang transmisi roda gigi karena sering menyebabkan terjadi kegagalan. Dibandingkan dengan analisa teoritik, menganalisa tegangan pada desain transmisi roda gigi dengan simulasi numerik akan memberikan keterengan lebih akurat dengan hasil tidak tidak jauh berbeda. Tujuan penelitian ini menganalisa tegangan bending dan tegangan kontak pada roda gigi serta tegangan geser pada poros bertingkat menggunakan metode silumasi numerik menggunakan perangkat lunak Ansys Workbench 14,5. Desain transmisi menggunakan dua pasang roda gigi dengan tiga poros yang menerima beban $1200 \mathrm{Nmm}$ pada poros pertama, 706 $\mathrm{Nmm}$ poros kedua, dan $456 \mathrm{Nmm}$ poros ketiga. Hasil dari penelitian ini menunjukkan tegangan bending terbesar terjadi pada akar gigi, tegangan kontak terbesar terjadi pada pitch line, sedangkan tegangan geser pada poros bertingkat terjadi pada diameter terkecil. Berdasarkan nilai keamanan, desain transmisi roda gigi yang dianalisa layak digunakan.
\end{abstract}

Kata Kunci : roda gigi lurus, tegangan bending, tegangan kontak

\begin{abstract}
:
The generator works optimally when the drive system sends turbine power with the appropriate rotation direction and speed. Bending stresses and contact stresses on the gears and shear stresses on the shaft need to be considered in designing gear transmissions because they often cause failures. Compared with theoretical analysis, analyzing stresses in the design of gear transmissions with numerical simulations will provide more accurate control with results not much different. The purpose of this study is to investigate the bending stress and contact stress on the gears and shear stress on the multilevel shaft using numerical simulation methods using Ansys Workbench 14.5 software. The transmission design uses two pairs of gears with three shafts that accept $1200 \mathrm{Nmm}$ loads on the first shaft, $706 \mathrm{Nmm}$ second shaft, and $456 \mathrm{Nmm}$ third shaft. The results of this study show that the greatest bending stress occurs at the root of the tooth, the largest contact voltage occurs in the pitch line, while the shear stress on the multilevel shaft occurs at the smallest diameter. Based on the value of safety, the design of the analyzed gear transmission is feasible.
\end{abstract}

Keywords : spur gear, bending stress, contact stress

\section{Pendahuluan}

Pico hydro merupakan pembangkit listrik tenaga air dengan daya maksimal yang dapat dihasilkan $5 \mathrm{Kw}$. Secara garis besar, sebagai pembangkit listrik pico hydro terdiri dari dua komponen pokok, yaitu turbin dan generator [1, 2]. Tegangan dan frekuensi akan dihasilkan generator dengan stabil apabila drive system dari turbin ke generator dengan arah dan kecepatan putaran yang sesuai. Untuk memenuhi kebutuhan kecepetan putar generator tersebut diperlukan sistem transmisi [3]. Transmisi dalam ilmu teknik mesin adalah sistem yang digunakan untuk mengubah kecepatan putar dan torsi. Putaran poros input akan mengubah putaran output lebih rendah atau yang lebih tinggi. Apabila kecepatan putar yang lebih lebih tinggi maka torsi yang akan dihasilkan akan menurun, sebaliknya apabila kecepatan putar yang lebih lebih rendah maka torsi yang akan dihasilkan akan naik [4].
Jenis dan model transmisi yang sering digunakan sebagai system drive antara lain, timing belt, sprocket, dan gearbox. Sedangkan dari beberapa tipe gearbox, yang mudah diaplikasikan roda gigi lurus [5]. Keunggulan roda gigi lurus terletak pada proses pembuatan dan biaya yang relatif lebih murah dan lebih mudah dibandingkan jenis roda gigi yang lain. Selain itu, roda gigi lurus cocok digunakan pada transmisi yang memiliki gaya keliling yang lebih besar, karena tidak menimbulkan gaya aksial [6].

Teknologi polymer yang telah berkembang sebagian mampu menggantikan teknologi logam, salah satunya dalam perancangan transmisi roda gigi beserta porosnya yang digunakan pada low power system. Keuntungan menggunakan material dari polymer antara lain benda lebih ringan, lebih senyap atau low noise, tidak korosi, dan proses pembuatan-nya yang lebih mudah serta lebih murah [7]. Terdapat beberapa 
material polymer yang memiliki sifat keras dan cocok digunakan sebagai material roda gigi, antara lain nylon 6 atau polyamide 6 karena memiliki kekuatan dan nilai efiseinsi yang baik [8].

Menganalisa beban dalam merancang roda gigi lurus sangat diperlukan, karena tegangan bending pada akar roda gigi saat terjadi benturan menyebabkan kegagalan yang berakibat patahnya gigi. Secara toritis tegangan bending dapat dianalisis menggunakan Persamaan Lewis dengan mengasumsikan gigi sebagai balok kantilever. Karena perancangan roda gigi lurus memiliki geometri yang rumit, menggunakan metode numerik akan memberikan analisa yang lebih akurat dibandingkan dengan metode teoritis [9]. Selain kegagalan gigi yang disebabkan tegangan bending, tegangan kontak juga perlu diperhatikan dalam merancang roda gigi lurus. secara teoritis dapat dianalisa menggunkan persamaan hertz dengan mengasumsikan dua buah permukaan radius silinder yang saling kontak [10]. Nilai safety factor atau nilai keamanan perlu diperhitungkan dalam merancang elemen mesin juga diperlukan untuk menahan beban dinamis. Pada perancangan roda gigi service factor diperlukan untuk menahan beban dinamis, dengan pembebanan yang diterima heavy shock dan beroperasi sehari penuh nilai service factor yang digunakan 2 [11].

Beberapa penelitian sebelumnya menyatakan dalam menganalisis tegangan bending [12-17] dan tegangan kontak $[10,18]$ pada roda gigi lurus menggunakan metode numerik menunjukkan hasil nilai tegangan maksimal yang tidak jauh berbeda dengan perhitungan secara teoritis. Hasil simulasi menggunakan metode numerik menunjukkan hasil distribusi tegangan maksimal terjadi pada akar gigi hal ini disebabkan pada akar terjadi pembebanan momen bending dan bentuk fillet pada akar gigi mangakibatkan konsentrasi di daerah tersebut semakin tinggi [9, 17-19]. Sedangkan tegangan kontak tertinggi terjadi pada pitch line atau involute hampir sepanjang lebar gigi hal ini disebabkan di daerah tersebut terjadi konsentrasi benturan paling tinggi pada area kontak $[10,18]$. Selain itu, pada hasil simulasi kekuatan poros, didapat tegangan terbesar pada poros terjadi pada diameter poros yang paling kecil, hal ini disebabkan pada diameter terkecil memiliki nilai inertia polar $(J)$ terkecil sedangkan nilai tegangan geser berbanding terbalik dengan nilai inertia polar $(J)[20]$.

Analisa tegangan bending dan tegangan kontak pada roda gigi dengan material polymer pernah dilakukan beberapa penelitian sebelumnya menggunakan metode simulasi numerik dan metode eksperimental. Bahan polymer tersebut meliputi acetal [21,22], PEEK, komposit serat gelas-epoxy [23]. Berdasarkan beberapa penelitian hasil simulasi numerik roda gigi dengan material polymer, kosentrasi tegangan bending dan tegangan kontak tertinggi tidak menunjukkan perbedaan dengan material dari logam dan komposit serat gelas-epoxy [23], yaitu tegangan bending pada akar gigi dan tegangan kontak pada bagian involute [21,23]. Hasil analisa simulasi numerik menunjukkan tidak adanya perbedaan dengan analisa eksperimental, pada pengujian eksperimental menunjukkan potensi kegagalan karena tegangan bending terjadi pada akar gigi, dan keausan terjadi pada bagian yang mengamali kontak antar gigi atau bagian involute atai pitch line [22]. Salah satu yang harus diperhatikan dalam merancang roda gigi adalah kekuatan material. Dalam perkembangannya, transmisi low power mulai bergeser dari material logam kearah polymer. Penelitian sebelumnya menunjukkan penggunaan material polymer yang bersifat keras pada roda gigi menunjukkan kelayakan yang baik terhadap beban bending dan beban kontak. Obyek dari penelitian ini terletak pada analisa distribusi tegangan bending dan tegangan kontak pada transmisi roda gigi dengan material polymer nylon 6 , serta analisa tegangan geser yang terjadi pada poros menggunakan material polyamide 6 , sehingga diketahui kelayakan roda gigi dan poros yang dirancang sebagai sistem transmisi melalui nilai keamananya. Secara langsung penelitian ini berkontribusi pada metode analisa kekuatan material roda gigi dan poros yang lebih akurat dan lebih detail dibandingkan analisa teortis. Selain itu dapat diketahui titik paling kritis atau kemungkinan terjadi kegagalan kerja pada design.

\section{Metode}

Desain transmisi pada penelitian ini terdiri dari dua pasang roda gigi lurus dengan tiga buah poros bertingkat masing-masing ditunjukkan Tabel 1 dan Tabel 2. Material yang digunakan pada roda gigi nylon 6 ,

Tabel 1. Spesifikasi roda gigi

\begin{tabular}{lcc}
\hline \multirow{2}{*}{ Nama Bagian } & \multicolumn{2}{c}{ Pasangan } \\
\cline { 2 - 3 } & Pertama & Kedua \\
\hline Lebar gigi & $17 \mathrm{~mm}$ & $17 \mathrm{~mm}$ \\
Module & 2.5 & 2.25 \\
Jumlah Gigi Driving & 25 & 22 \\
Jumlah Gigi Driven & 14 & 14 \\
Diameter Roda Gigi & $35 \mathrm{~mm}$ & $31,5 \mathrm{~mm}$ \\
Driving & & \\
Diameter Roda Gigi & $62,5 \mathrm{~mm}$ & $49,5 \mathrm{~mm}$ \\
Driven & & \\
Addendum & $2,5 \mathrm{~mm}$ & $2,25 \mathrm{~mm}$ \\
Dedendum & 3,125 & 2,8125 \\
& $\mathrm{~mm}$ & $\mathrm{~mm}$ \\
\hline
\end{tabular}

sedangkan pada poros menggunakan polyamide 6 . Masing-masing roda gigi dan poros mengalami pembebanan torsi, yaitu :

a. Pada poros input beban yang diterima 1200 $\mathrm{Nmm}$ menggerakkan roda gigi driving pada roda gigi pasangan pertama. 
b. Pada poros tengah beban yang diterima 706 $\mathrm{Nmm}$ menggerakkan roda gigi driving pada roda gigi pasangan kedua.

c. Pada poros output beban yang diterima 465 $\mathrm{Nmm}$

Tabel 2. Ukuran Poros Bertangga

\begin{tabular}{ccc}
\hline Poros & Diameter kecil & Diameter besar \\
\hline Input & $16 \mathrm{~mm}$ & $19 \mathrm{~mm}$ \\
Tengah & $13 \mathrm{~mm}$ & $15 \mathrm{~mm}$ \\
Ouput & $11 \mathrm{~mm}$ & $14 \mathrm{~mm}$ \\
\hline
\end{tabular}

Analisa numerik yang digunakan pada penelitian ini menggunakan perangkat lunak metode elemen hingga tiga dimensi ansys workbench 14,5 dengan beberapa pengaturan meshing dan penentuan kondisi batasnya.

\section{Pengaturan Meshing}

Pengaturan meshing digunakan untuk membagi bagian struktur atau komponen menjadi beberapa node dan element. Pengaturan meshing yang digunakan pada roda gigi dan poros sebagai berikut:

- Relevance $=$ Medium

- Element Size = Default

- Smothing = Medium

- Span Angle Center $=$ Coarse

Pada konsetrasi tegangan kontak roda gigi lurus juga terdapat meshing, pengaturan yang digunakan yaitu dengan tools contact sizing, dengan type bonded symmetric dan elemen size $0,4 \mathrm{~mm}$.

\section{Kondisi Batas}

Penentuan kondisi batas pada roda gigi seperti yang ditunjukkan Gambar 1 bagian roda gigi driving tumpuan yang digunakan cylindrical support dengan pengaturan sumbu axial dan radial fixed, sumbu tangensial free. Pada roda gigi driven tumpuan yang digunakan fixed. Beban yang digunakan adalah beban torsi.

Sedangkan pada poros seperti yang ditunjukkan Gambar 2 digunakan fixed pada ujung poros. Beban yang digunakan poros adalah beban torsi.

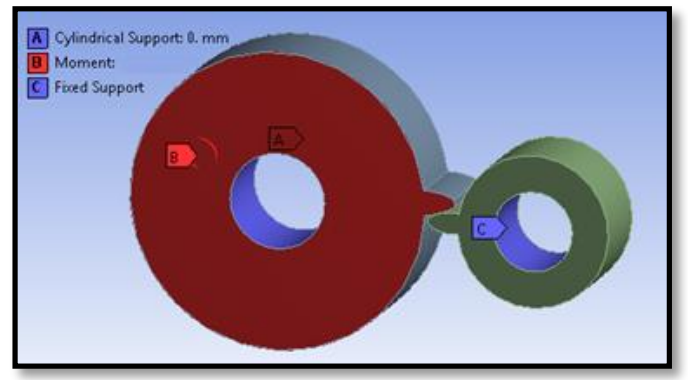

Gambar 1. Kondisi batas pada roda gigi

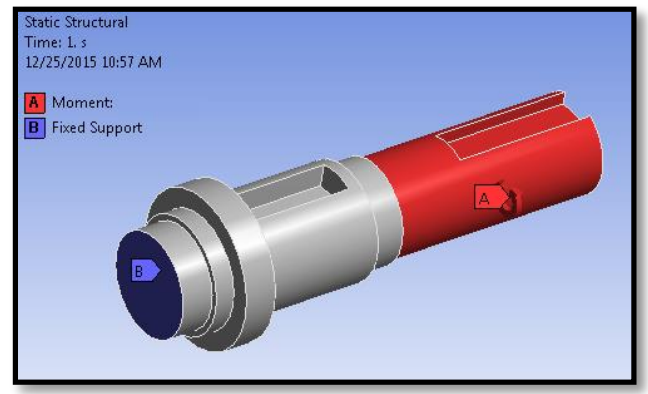

Gambar 2. Kondisi batas pada poros

\section{Hasil dan Pembahasan}

\section{Distribusi Tegangan pada Roda Gigi}

Hasil tegangan yang diperoleh dari simulasi ansys pada roda gigi adalah titik kritis dengan nilai tegangan bending dan tegangan kontak maksimal yang terjadi dengan ditunjukkan kontur warna merah.

Pada pasangan roda gigi pertama beban yang diterima adalah $1200 \mathrm{Nmm}$. Tegangan bending maksimal yang terjadi pada roda gigi driving sebesar $8,1833 \mathrm{MPa}$ terjadi akar gigi yang ditunjukkan Gambar 4, sedangkan pada roda gigi driven sebesar $6,1453 \mathrm{MPa}$ terjadi pada akar gigi yang ditunjukkan Gambar 5. Tegangan kontak maksimal pada pasangan roda gigi pertama terjadi pada roda gigi driving sebesar 15,415 $\mathrm{MPa}$ terjadi disekitar pitch line contact hampir sepanjang lebar gigi ditunjukkan Gambar 6.

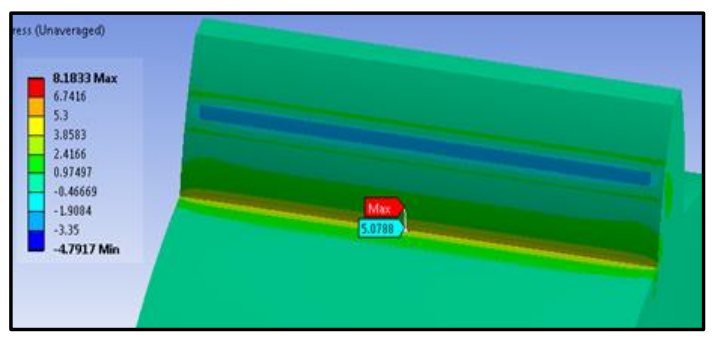

Gambar 3. Distribusi tegangan roda gigi driving pada pasangan roda gigi pertama

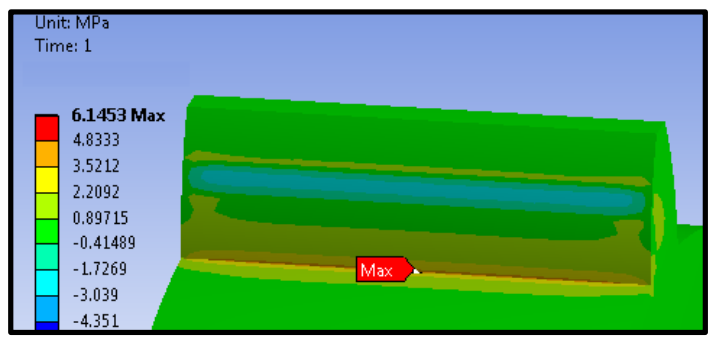

Gambar 4. Distribusi tegangan roda gigi driven pada pasangan roda gigi pertama 


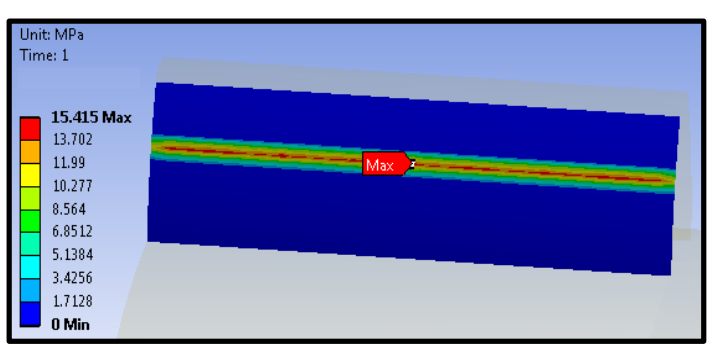

Gambar 5. Distribusi tegangan kontak pada pada pasangan roda gigi pertama

Pada pasangan roda gigi kedua beban yang diterima adalah $706 \mathrm{Nmm}$. Tegangan bending maksimal yang terjadi pada roda gigi driving sebesar 5,9214 $\mathrm{MPa}$ yang terjadi pada akar gigi ditunjukkan Gambar 7, sedangkan pada roda gigi driven sebesar 4,4135 $\mathrm{MPa}$ yang terjadi pada akar roda gigi ditunjukkan Gambar 8. Tegangan kontak maksimal pada pasangan roda gigi kedua terjadi pada roda gigi driving sebesar $10,8510 \mathrm{MPa}$ disekitar pitch line contact hampir sepanjang lebar roda gigi ditunjukkan Gambar 9.

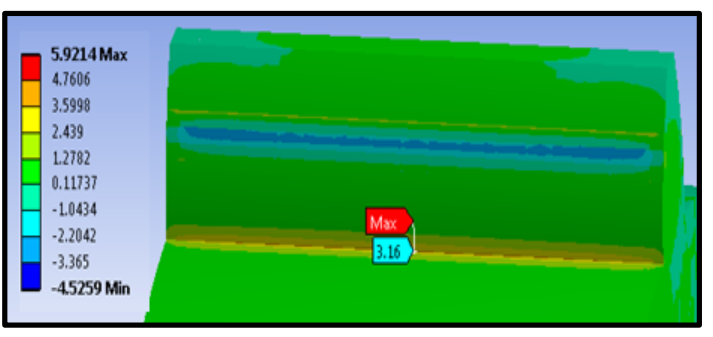

Gambar 6. Distribusi tegangan roda gigi driving pada pasangan roda gigi kedua

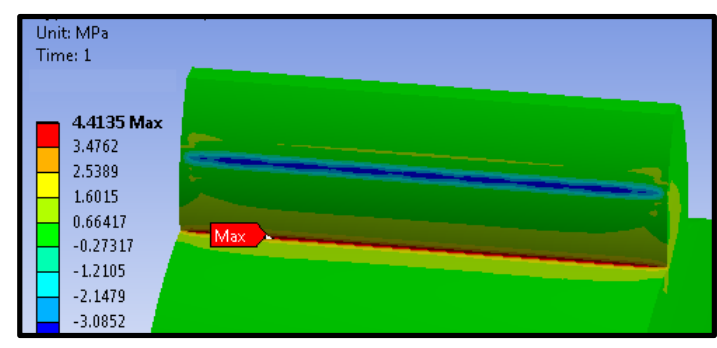

Gambar 7. Distribusi tegangan roda gigi driven pada pasangan roda gigi kedua

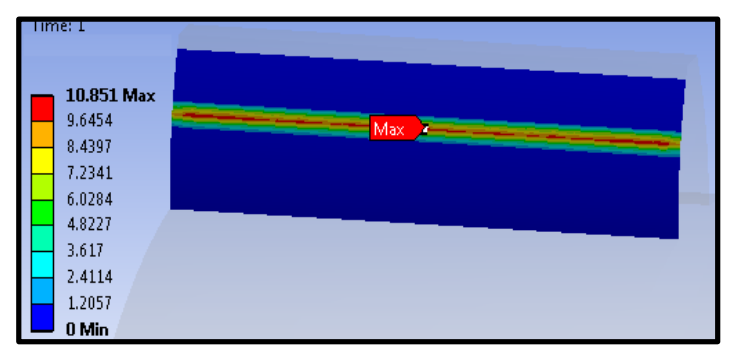

Gambar 8. Distribusi tegangan kontak pada pada pasangan roda gigi kedua
Gambar 4, 5, 7, 9 menunjukkan tegangan pada roda gigi driving maupun driven yang terjadi pada bagian akar gigi, hal ini sesuai dengan penelitian dengan metode simulasi numerik yang dilakukan oleh Marciniec dkk., (2009) tegangan bending tertinggi roda gigi terjadi pada akar gigi yang disebabkan terjadi pembebanan momen bending maksimum, serta bentuk fillet atau melengkung menyebabkan konsentrasi di daerah tersebut menjadi tinggi [18]. Rajeshkumar dkk., (2019) pada penelitiannya menggunakan simulasi numerik menyatakan tegangan bending terbesar pada roda gigi dengan material logam, polymer, dan komposit serat gelasepoxy menunjukkan hasil yang sama, yaitu pada akar gigi [23].

Sedangkan Gambar 6 dan 9 menunjukkan tegangan kontak maksimal terjadi pada bagian pitch line hampir sepanjang lebar gigi, hal ini sesuai dengan penelitian dengan metode simulasi numerik yang dilakukan oleh Langlois dkk., (2017) tegangan kontak tertinggi roda gigi dengan material polymer dalam keadaan statis daerah terjadi pada involute atau pitch line merupakan daerah dengan konsentrasi benturan paling tinggi pada area kontak gigi [21].

\section{Distribusi Tegangan pada Poros}

Hasil tegangan yang diperoleh dari simulasi ansys pada poros adalah titik kritis dengan nilai tegangan geser maksimal yang terjadi dan ditunjukkan dengan kontur warna merah.

Pada poros input beban yang diterima adalah 1200 Nmm memiliki tegangan maksimal yang terjadi sebesar 1,7192 MPa yang ditunjukkan Gambar 10 . Pada poros tengah beban yang diterima adalah 706 $\mathrm{Nmm}$ memiliki tegangan maksimal yang terjadi sebesar 1,5399 MPa yang ditunjukkan Gambar 11 . Pada poros output beban yang diterima adalah 465 $\mathrm{Nmm}$ memiliki tegangan maksimal yang terjadi sebesar 1,7688 MPa yang ditunjukkan Gambar 12 .

Berdasarkan Gambar 10, 11, dan 12, masing-masing dapat dilihat tegangan terbesar yang terjadi pada poros input, tengah maupun output terjadi pada bagian poros yang berdiameter paling kecil. Hal ini sesuai dengan penelitian yang dilakukan secara simulasi numerik oleh Cojocaru dkk., (2014) tegangan geser terbesar pada poros bertingkat terjadi

pada poros dengan diameter terkecil, hal ini disebabkan pada diameter terkecil memiliki nilai inertia polar $(J)$ terkecil, sedangkan nilai tegangan geser yang terjadi berbanding terbalik dengan nilai inertia polar $(\mathbf{J})[20]$. 


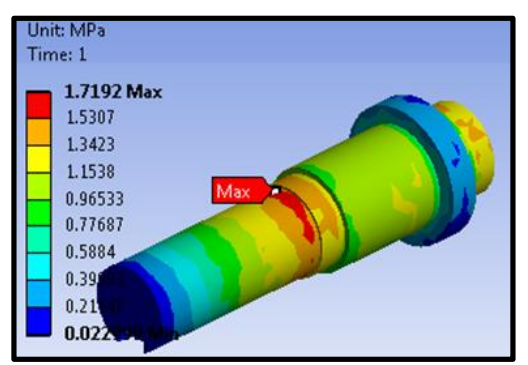

Gambar 9. Distribusi tegangan poros input

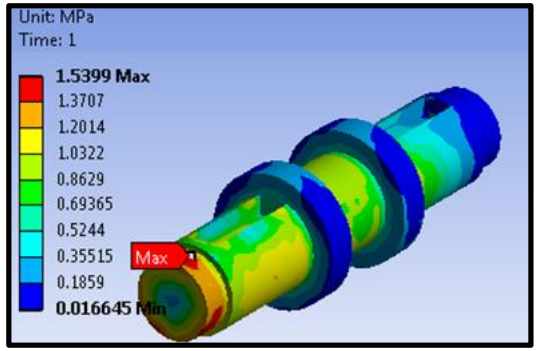

Gambar 10. Distribusi tegangan poros tengah

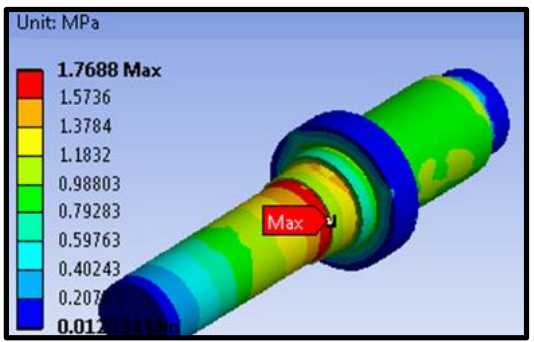

Gambar 11. Distribusi tegangan poros output

\section{Nilai Keamanan}

Pada roda gigi secara berturutan pasangan pertama dan kedua memiliki nilai keamanan minimal nilai 5,3533 dan 8,6250 yang ditunjukkan pada Gambar 13 dan Gambar 14 Sedangkan pada poros secara berturutan poros input, tengah, dan output memiliki nilai keamanan 4,0717, 4,5457, dan 3,9574 yang ditunjukkan Gambar 15, 16, 17.

Berdasarkan nilai keamanan pada roda gigi dan poros dengan masing-masing pembebanan torsi yang diterima, pada poros output memiliki nilai keamanan terendah yaitu 3,9574. Komponen atau part dengan nilai keamanan paling rendah merupakan titik yang paling lemah dari suatu struktur dan memiliki peluang terbesar terjadi kegagalan kerja [24]. Berdasarkan hal tersebut poros output yang merupakan titik paling kritis dari struktur sehingga peluang terbesar kemungkinan terjadi kegagalan kerja pada sistem transmisi ini.

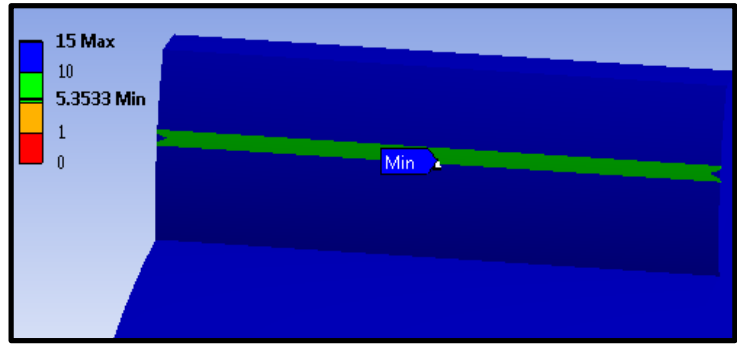

Gambar 12. Nilai keamanan roda gigi pasangan pertama

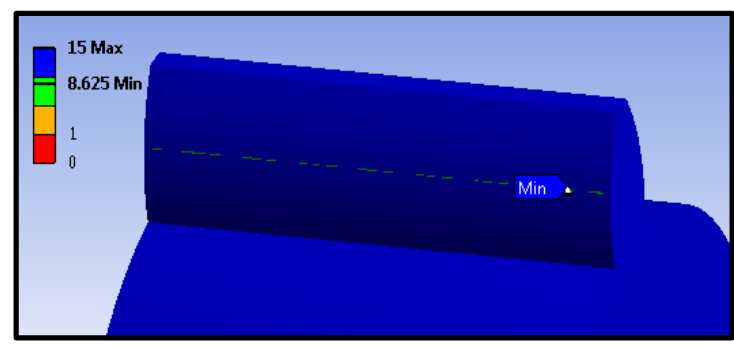

Gambar 13. Nilai keamanan roda gigi pasangan kedua

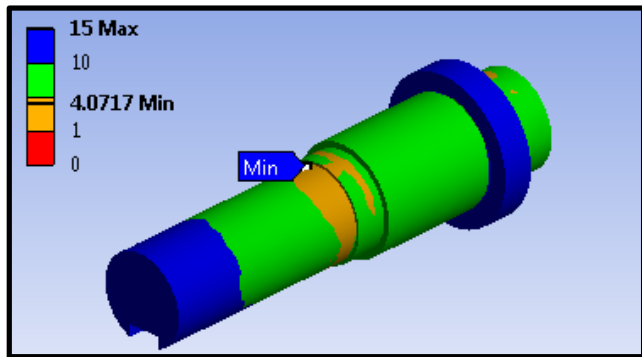

Gambar 14. Nilai keamanan poros input

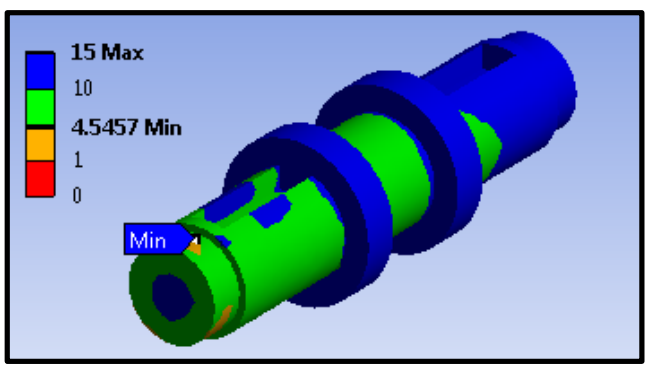

Gambar 15. Nilai keamanan poros tengah

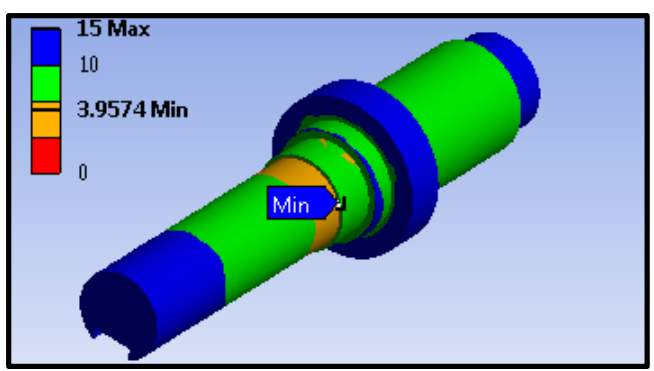

Gambar 16. Nilai keamanan poros output 


\section{Kesimpulan}

Dari simululasi studi numerik yang telah dilakukan secara detail didapat tegangan bending dan tegangan kontak roda gigi masing-masing terbesar terletak pada akar gigi dan pitch line. Sedangkan pada poros tegangan geser terbesar terletak pada diameter terkecil. Titik paling kritis pada roda gigi terletak pada pitch line yang disebabkan tegangan kotak antar gigi, sedangkan pada poros terletak pada diameter poros output yang paling kecil. Berdasarkan analisa yang telah dilakukan dengan nilai keamanan komponen terkecil 3,9574 diatas syarat nilai minimal service factor, desain transmisi layak digunakan.

\section{Daftar Pustaka}

[1] A. Z. S, "Redesign runner turbin pembangkit listrik tenaga pico hydro dengan metode reverse engineering melalui pendekatan teoritis," vol. 12, no. 2, pp. 61-65, 2016.

[2] H. P. Dewanto, D. A. Himawanto, and D. Danardono, "Pembuatan dan pengujian turbin propeller dalam pengembangan teknologi pembangkit listrik tenaga air piko hidro ( PLTA-PH ) dengan variasi debit aliran," vol. 12, no. 2, pp. 54-62, 2017.

[3] S. Davis and S. Graham, Micro Hydro-power Systems: A Buyerís Guide. Her Majesty the Queen in Right of Canada. 2004.

[4] A. Bhatia, "Basic Fundamentals of Gear Drives," no. 877.

[5] Herbert S. Cheng. Introuction of Gears. 2001.

[6] Yefri Chan,ST.MT. Teori Dasar Roda Gigi dan Sambungan Pasak (Keys). Universitas Darma Persada.

[7] A. D. Dighe, A. K. Mishra, and V. D. Wakchaure, "Investigation of Wear Resistance and Torque Transmission Capacity of Glass Filled Polyamide and PEEK Composite Spur Gears," no. 3, pp. 299-303, 2014.

[8] S. Kirupasankar, C. Gurunathan, and R. Gnanamoorthy, "Transmission efficiency of polyamide nanocomposite spur gears," Mater. Des., vol. 39, pp. 338-343, 2012.

[9] S. H. Din, "Failure Analysis and Investigation of bending stress on a gear tooth at design stage by finite element modelling Investigation of Bending Stress on a Spur Gear Tooth at Design Stage by Finite Element Modelling," no. June, 2018.

[10] P. S. Rao, "Contact Stress and Shear Stress Analysis of Spur Gear Using ANSYS and Theoretical," vol. 2, no. 2, pp. 9-14, 2016.

[11] Sularso, K. Suga. 1997. Dasar Perencanaan dan Pemilihan Elemen Mesin. Cetakan kesembilan, Pradnya Paramita, Jakarta

[12] S. P. Shinde, A. A. Nikam, and T. S. Mulla, "Static Analysis of Spur Gear Using Finite
Element Analysis," pp. 26-31.

[13] R. K. Rathore, "Bending Stress Analysis \& Optimization of Spur Gear," vol. 3, no. 5, pp. 2044-2049, 2014.

[14] A. Patil, "Bending Stress Analysis of Spur Gear," vol. 5, no. Vi, pp. 422-426, 2017.

[15] S. Prabhakaran, D. S. Balaji, and R. P. Kumar, "Bending Stress Analysis Of A Spur Gear For Material Steel 15ni2cr1mo28," vol. 12, no. 19, pp. 5636-5641, 2017.

[16] S. Damtie and D. Tilahun, "Contact Stress Analysis Of Involute Spur Gear By Finite Element Method ( FEM ) Shiferaw Damtie and Daniel Tilahun Materials Gear Specifications Table 2: Spur Gear Specification Modeling," pp. 33-40.

[17] I. Atanasovska, "3d Spur Gear Fem Model For The Numerical Calculation Of Face Load Factor," vol. 6, no. 045, pp. 131-143, 2007.

[18] A. Marciniec and A. Pawlowicz, "The Bending And Contact Stress Analysis Of Spur Gears," vol. 16, no. 3, 2009.

[19] M. Z. Rizal and A. S. Pramono, "Studi Kekuatan Spur Gear dengan Profil Gigi Asymmetric Involute dan Symmetric Involute," vol. 1, no. 2, pp. 1-6, 2014.

[20] V. Cojocaru and A. O. Cantaragiu, "Finite Element Analysis Of Stresses Distributions On The Shafts And," vol. 45, pp. 5-8.

[21] Langlois, Paul. 2017. "Tooth Contact Analysis - Off Line of Action Contact and Polymer Gears," no. October: 84-91.

[22] Yousef, Samy, T A Osman, M Khattab, Ahmed A Bahr, and Ahmed M Youssef. 2015. "A New Design of the Universal Test Rig to Measure the Wear Characterizations of Polymer Acetal Gears ( Spur, Helical, Bevel , and Worm )" 2015.

[23] S Rajeshkumar and R Manoharan. 2017. "Design and Analysis of Composite Spur Gears Using Finite Element Method Design and Analysis of Composite Spur Gears Using Finite Element Method." https://doi.org/10.1088/1757899X/263/6/062048.

[24] Anggi Kurniawan. Skripsi: Analisa Kekuatan Struktur Crane Hook dengan Perangkat Lunak Elemen Hingga untuk Pembebanan 20 Ton. 2014. Program Studi Teknik Mesin Fakultas Teknik Universitas Bengkulu. 